\title{
O TRATAMENTO ADEQUADO DAS CUSTAS PROCESSUAIS COMO INSTRUMENTO DE GESTÃO PROCESSUAL
}

\author{
PROPER TREATMENT OF PROCEDURAL COSTS AS A \\ PROCESSUAL MANAGEMENT INSTRUMENT
}

\begin{abstract}
RAFAEL SOUZA CARDOZO
Mestrando do PPGPD/Enfam. Bacharel em direito pela Faculdade de Direito Milton Campos/MG. Juiz de direito do TJPE. Membro efetivo do Centro de Inteligência do TJPE. Professor da Esmape e integrante do Banco Nacional de

Formadores da Enfam. https://orcid.org/0000-0002-1702-5488
\end{abstract}

\begin{abstract}
RESUMO
O presente trabalho tem como objetivo analisar os efeitos do sistema atual de custas processuais no Judiciário brasileiro na perspectiva da análise econômica do direito e da gestão processual. A partir da pesquisa bibliográfica documental, em especial da análise de dados do Poder Judiciário, verifica-se que as custas processuais são um elemento que impacta diretamente na decisão de litigar. As baixas custas processuais e o financiamento estatal no patamar de $90 \%$ servem de estímulo ao ajuizamento de novas demandas, à sobreutilização do Judiciário, à subutilização dos métodos alternativos e à interposição de recursos. Conferir tratamento adequado às custas processuais perpassa pela aproximação do seu valor ao custo efetivo do processo e pela atuação do magistrado gestor, que deve exercer efetivo controle com vistas à concessão de uma tutela judicial justa e efetiva.
\end{abstract}

Palavras-chave: custas processuais; análise econômica do direito; financiamento público; custo efetivo do processo; magistrado gestor.

\begin{abstract}
The work aims to analyze the impact of the current system of procedural costs in the Brazilian Judiciary from the perspective of economic analysis of law and procedural management. From the documentary bibliographic
\end{abstract}


research, especially from the analysis of data from the Judiciary, it appears that the procedural costs are an element that directly impacts the decision to litigate. The low procedural costs and state funding at the level of $90 \%$ serve as a stimulus for filing new demands, the overuse of the Judiciary, the underutilization of alternative methods and the interposition of appeals. Providing adequate treatment at procedural costs involves the approximation of its value to the effective cost of the process and the performance of the magistrate-manager, who must exercise effective control over legal costs in order to grant fair and effective judicial protection.

Keywords: procedural costs; law and economics; public funding; cost effective process; magistrate-manager.

Recebido: 24-5-2021

Aprovado: 28-6-2021

\section{SUMÁRIO}

1 Introdução. 2 A análise econômica do direito: breves considerações. 30 financiamento coletivo do processo judicial e a sobreutilização do judiciário pelos grandes litigantes. 4 Um novo olhar sobre o acesso à justiça: breve reflexão. 5 A gestão processual por intermédio das custas processuais: correção de dados processuais, gratuidade da justiça e interesse recursal. 6 Conclusão. Referências.

\section{INTRODUÇÃO}

A taxa judicial e as custas judiciais são tributos pagos em virtude da utilização, efetiva ou potencial, de um serviço público, específico e divisível - no caso, a decisão adjudicatória pelo Poder Judiciário?. Enquanto aquela tem como fato gerador a prestação de serviços públicos judiciais, esta tem nos diversos atos processuais e cartorários sua hipótese de incidência. Sobre essa distinção, rememora-se o leading case do Supremo Tribunal Federal - STF, a Representação n. 1.077/RJ, ainda aplicável à ordem constitucional vigente, em que o Ministro Moreira Alves assentou:

\footnotetext{
"Art. 77. As taxas cobradas pela União, pelos Estados, pelo Distrito Federal ou pelos Municípios, no âmbito de suas respectivas atribuições, têm como fato gerador o exercício regular do poder de polícia, ou a utilização, efetiva ou potencial, de serviço público específico e divisível, prestado ao contribuinte ou posto à sua disposição." (BRASIL, 2007)
} 
Portanto, não só com base na tradição da técnica do direito brasileiro, mas também da legislação federal a ela pertinente, verifica-se que a taxa judiciária é a taxa que se adstringe aos serviços forenses - "é um tributo pago pelo autor para ter direito à atividade dos órgãos judiciários" -, ao passo que as custas e emolumentos (denominados, as mais das vezes, com relação às retribuições pelos atos extrajudiciais, como emolumentos apenas) dizem respeito às despesas de movimentação dos atos judiciais ou extrajudiciais e ao salário ou remuneração dos serventuários cartorários excluídos, portanto, o juiz (este, inclusive, por força da vedação do artigo 114, II, da Constituição) e o Ministério Público - que os realizam.

A taxa judiciária, inclusive pelo sistema constitucional vigente - em que ela, custas e emolumentos são exclusivamente remuneratórios de serviços prestados pelo Estado - só se justifica como contraprestação à atuação de órgãos da Justiça (assim, o juiz e o Ministério Público, quando não é parte) cujas despesas não são cobertas por custas e emolumentos. (BRASIL, 1984)

Apesar da distinção jurídica, no presente artigo, utilizar-se-á a expressão "custas"/"custas processuais" para englobar tanto a taxa judicial como as custas judiciais, significando o valor gasto para ingressar com uma ação no Judiciário, excluídos eventuais honorários contratuais.

De acordo com o diagnóstico realizado pelo Conselho Nacional de Justiça - CNJ (BRASIL, 2019), as custas possuem duas funções: 1) fonte de recurso e de custeio da prestação jurisdicional; e 2) papel educativo e de mitigação do abuso do direito de acesso ao Judiciário. É sobre esse segundo ponto que o presente artigo se desenvolverá sob o viés da gestão processual e do controle de entrada de novos processos no Judiciário.

O Poder Judiciário há anos se depara com a chamada "crise do Judiciário", sintetizada, em linhas gerais, como sendo a ineficiência da prestação jurisdicional, marcada pela morosidade excessiva, pela litigiosidade explosiva, pelo aumento de novos casos a cada ano e pela alta taxa de congestionamento.

O último relatório (BRASIL, 2020a) da Justiça em Números do CNJ apontou que, em 2019, houve um aumento de 6,8\% de novos casos em comparação a 2018, o que representa 30,2 milhões de novas ações, e que o estoque, na Justiça brasileira, é de 77,1 milhões de processos 
em tramitação. A atual taxa de congestionamento é de 68,5\%, o que significa que apenas $31,5 \%$ de todos os processos que tramitavam foram solucionados.

Entre os fatores que culminaram na crise do Judiciário, que são diversos, não excludentes e carecem de estudo empírico (GICO JR, 2014, p. 163-198), este artigo abordará a ideia de que as custas processuais - que, na sistemática atual, não correspondem ao custo efetivo do processo - podem ser consideradas um elemento de estímulo à litigância, na perspectiva da análise econômica do direito.

A ausência de tratamento adequado aos custos processuais, que inclui a atuação gestora do magistrado, e aos incentivos à não judicialização acarreta um acesso abusivo e irresponsável ao Judiciário. (PIMENTEL, 2017)

o presente artigo, quanto à metodologia, baseou-se na pesquisa bibliográfica documental para a construção teórica sobre a matériaalvo do estudo e se desenvolverá em seis tópicos, iniciando com esta introdução. Na segunda seção, será feita uma breve abordagem da análise econômica do direito e sua importância para a gestão judicial. No tópico seguinte, será analisado o custo efetivo de um processo judicial e sua correspondência com os valores das custas processuais, os grandes litigantes e o impacto dessa equação no Judiciário. No quarto capítulo, será revisitado o acesso à Justiça sob a ótica do "acesso à ordem jurídica justa”, expressão cunhada por Kazuo Watanabe (2019a). No item cinco, será abordado o tema das custas processuais como instrumento de gestão processual e os possíveis benefícios para o Judiciário, com destaque para a importância do magistrado gestor. Por fim, no sexto tópico, serão apresentadas as conclusões. Com esse percurso, será possivel compreender a importância de se conferir às custas processuais tratamento adequado e que possibilite o "acesso à ordem jurídica justa" e a gestão processual.

Registra-se que este artigo não pretende exaurir a discussão quanto às alterações legislativas necessárias para o tratamento adequado das custas processuais, como hipóteses de incidência, isenções, tratamentos diferenciados em virtude de ser um litigante habitual ou esporádico, momento de cobrança etc., sobretudo porque tais nuances constam de proposta legislativa enviada pelo CNJ ao Congresso Nacional (MONTENEGRO, 2020). O objetivo é fomentar o debate acerca do tema e possibilitar a formação de uma consciência sobre a matéria, principalmente sua importância do ponto de vista da gestão processual. 


\section{A ANÁLISE ECONÔMICA DO DIREITO: BREVES CONSIDERAÇÕES}

A análise econômica do direito, também conhecida como law and economics, tem origem no direito norte-americano e, em linhas gerais, fundamenta-se no estudo do direito, em especial do conflito, suas causas e efeitos, com base em variáveis eminentemente econômicas, oriundas da teoria da microeconomia, em especial, da teoria da escolha racional. (FUX, 2021)

Utiliza-se o método econômico para analisar o direito com o intuito de compreender, explicar e prever situações fáticas no ordenamento jurídico, em uma perspectiva de custos e benefícios que possui três pressupostos: preferências, escassez e racionalidade. (GICO JR., 2020)

As partes envolvidas em um conflito possuem preferências que decorrem de questões internas, subjetivas e culturais, enquanto os bens jurídicos controvertidos são escassos - do contrário, não haveria conflito. A equalização entre preferências e escassez decorre da escolha racional, de modo que a parte escolhe o que irá perseguir e como alcançará seu objetivo. Nas palavras de Ivo Teixeira Gico Jr. (2020, p. 77-78):

De acordo com a TER [Teoria da Escolha Racional], os indivíduos são motivados por seus desejos e objetivos pessoais (preferências). No entanto, dado que não é possível satisfazer todo e qualquer desejo (escassez), os individuos devem fazer uma escolha acerca de quais objetivos buscarão e quais meios utilizarão para alcançar tais objetivos. Justamente por isso, os indivíduos tentam estimar, de acordo com as informações disponíveis, os prováveis resultados de cada curso de ação disponível (retorno esperado) e adotam a conduta que, na opinião deles, os aproximará mais de seus objetivos, i.e., que Ihes dará mais satisfação (utilidade). Como escolhas devem ser feitas, as pessoas se comportam como se ponderassem os custos e os benefícios de cada alternativa, adotando a conduta que, dada às suas condições e circunstâncias, Ihe parece trazer mais bem-estar. Dizemos, então, que a conduta dos agentes é racional maximizadora.

Conclui o citado autor que as pessoas respondem a incentivos, inclusive do ponto de vista jurídico-processual, englobando nesse viés os custos para o ajuizamento da demanda judicial, elemento essencial 
que impacta na decisão racional de litigar e no número de novos processos no Judiciário.

Nessa perspectiva, a análise econômica do direito constitui importante modelo teórico para a gestão judicial a fim de se examinar quais os incentivos (positivos ou negativos) encontram-se à disposição da parte envolvida no conflito, seja no que tange ao ajuizamento da ação, seja no que se refere à elaboração de um acordo, à interposição de um recurso ou mesmo à escolha da Alternative Dispute Resolution - ADR² em vez do sistema adversarial.

A análise econômica do direito permite, pois, a percepção da atividade judicial sob a ótica de uma empresa que presta um serviço - no caso, a decisão adjudicatória -, com todas as suas variáveis econômicas, como metas, gestão, custos, receitas, produtividade, qualidade, tempo do serviço, limite de capacidade produtiva etc., na busca da eficiência da prestação jurisdicional.

\section{O FINANCIAMENTO COLETIVO DO PROCESSO JUDICIAL E A SOBREUTILIZAÇÃO DO JUDICIÁRIO PELOS GRANDES LITIGANTES}

O atual sistema de custeio de um processo judicial é misto (BRASIL, 2019), ou seja, uma parcela dos custos é paga pelas partes demandantes e outra parcela é financiada pelo Estado, por meio de impostos. No entanto, a parcela paga pelos demandantes é muito aquém dos efetivos custos de um processo, o que gera um desequilíbrio considerável nas despesas do Poder Judiciário e contribui para o aprofundamento da crise do Judiciário. Sobre essa sistemática, explica Hipólito Gadelha Remígio:

[...] pretende-se, inicialmente, que o interessado no processo arque com os seus custos, porém, cobra-se dele um montante absolutamente insuficiente para fazer face às necessidades do Poder Judiciário, o que impõe a maior parte do custeio sobre a totalidade da sociedade. (REMÍGIO, 2002, p. 7)

\footnotetext{
2 ADR, do inglês Alternative Dispute Resolution, representa o conjunto de formas alternativas de resolução de conflitos, englobando a mediação, a negociação, a arbitragem e a conciliação, mas não se limitando a esses fatores.
} 
O custo médio de um processo é de $\mathrm{R} \$ 3.317,80^{3,4}$, ao passo que a arrecadação com taxa judicial e custas processuais é de, em média, $\mathrm{R} \$ 1.110,88$ (BRASIL, 2020), de modo que o valor pago por um processo corresponde a 30\% do seu custo efetivo. Se considerarmos aqueles processos cujo valor da causa é de até $\mathrm{R} \$ 20.000,00$, a arrecadação com custas processuais cai para $\mathrm{R} \$ 676,86$ (BRASIL, 2019) e a desproporção entre o valor pago e o efetivo sobe para $80 \%$.

O custo total da Justiça em 2019 foi de R \$ 100,2 bilhões, enquanto a arrecadação com custas, emolumentos e taxas foi de apenas 13,1 bilhões (BRASIL, 2020a), o que permite concluir que $R \$ 87,1$ bilhões foram custeados pela coletividade. Em outras palavras, as custas processuais, que, a princípio, deveriam cobrir a maioria das despesas do Poder Judiciário, em verdade, respondem, tão somente, por 13\% do custo da Justiça.

Há, portanto, um financiamento público na ordem de $87 \%$ e cada brasileiro paga, em média, $\mathrm{R} \$$ 479,16 para que o Judiciário possa funcionar, ainda que jamais tenha litigado em juízo.

Como serviço público adjudicatório, não se defende que não haja contraprestação pelo Estado nos custos da Justiça ou lucro com esse serviço. Contudo, deve-se buscar a diminuição desse financiamento público, aproximando o valor das custas processuais ao preço efetivo do processo, sob pena de haver um colapso do Judiciário em virtude da sua sobreutilização.

Isso porque subsidiar as custas processuais significa incentivar a propositura de ações judiciais, desestimulando a prevenção dos

\footnotetext{
3 Conforme explica Tabak (2017, p. 458-481), o Conselho Nacional de Justiça, "mesmo possuindo todos os dados de processos e de custeio dos órgãos judicias, não ousa apresentar o efetivo 'custo do processo', que se daria, aparentemente, com uma divisão simples do valor total dos custos pelo número de processos". Diante dessa lacuna, o autor sugere dividir o valor total das despesas pelo número de processos novos para chegar ao custo de um processo. Adotando-se a referida operação matemática, com base nos dados do Justiça em Números 2020 (BRASIL, 2020), chega-se ao custo de $\mathrm{R} \$ 3.317,80$ por processo.

4 Se adotada a metodologia (XIMENES, 2015) utilizada pelo Centro de Pesquisa sobre o Sistema de Justiça Brasileiro (CPJus) do Instituto Brasileiro de Direito Público (IBDP) e, com base nos dados do Justiça em Números 2020 (BRASIL, 2020a), o custo médio de um processo é de $\mathrm{R} \$ 2.830,50$.
} 
conflitos e sua resolução por vias alternativas (PIMENTEL, 2017) (sistema multiportas ${ }^{5}$ ), sobretudo com relação aos grandes litigantes.

Em 2011, o CNJ (BRASIL, 2012) realizou levantamento por meio do qual identificou que os maiores litigantes da Justiça brasileira, com exceção dos entes públicos, são as instituições financeiras e as empresas de telefonia, de seguros e previdência e de planos de saúde.

No mesmo sentido, pesquisa da Fundação Getulio Vargas - FGV de autoria de Wilson Pimentel (2017) apontou que os 30 maiores litigantes do Tribunal de Justiça do Rio de Janeiro (TJ/RJ) respondem por quase 90\% das ações ajuizadas. Tal dado, aliás, mostra a importância de os tribunais adotarem mecanismos de gestão para a correta identificação e monitoramento de seus grandes litigantes, em virtude do impacto da ação desses agentes no sistema de Justiça local, inclusive para mapear eventuais demandas predatórias e repetitivas.

Conforme explica o citado autor, na perspectiva da teoria dos jogos $^{6}$, os grandes litigantes, pelo volume de ações, desenvolvem maiores expertises em comparação aos litigantes esporádicos e, portanto, entendem melhor as "regras do jogo" e se tornam mais sensíveis à eventual alteração no tratamento das custas.

Nesse contexto de subvenção estatal dos custos processuais e de monopólio da via adversarial pelos grandes litigantes, pode-se afirmar que a população brasileira financia os bancos e as empresas que prestam serviços públicos, como as de telefonia, que, por sua vez, sobrecarregam o sistema de Justiça e, por vias transversas, diminuem a possibilidade de o cidadão ter uma solução rápida do seu conflito, impactando negativamente no "acesso à ordem jurídica justa".

financiamento público gera um efeito reverso do que preconiza o modelo processual civil vigente de incentivo à autocomposição e gera um estímulo para o ajuizamento de ações que não existiriam se os grandes

\footnotetext{
5 Segundo Helio Antunes Carlos e Renan Sena Silva (2019, p. 35), "[...] um modelo de Justiça Multiportas deve considerar a multiplicidade de portas para a solução do conflito, de sorte que o ajuizamento de uma ação perante o Poder Judiciário se apresenta apenas como uma das portas disponíveis. A noção de Justiça Multiportas deve considerar o papel de todos os atores envolvidos na solução de conflitos - seja no âmbito judicial ou no extrajudicial -, de modo a considerar as variadas portas de entrada e de saída para o tratamento do conflito".

6 Em breves linhas, a "teoria dos jogos" ou "teoria das interações estratégicas" é uma teoria matemática que propicia modelar os comportamentos dos agentes envolvidos no processo decisório no que tange à racionalidade das escolhas. (MACKAAY; ROUSSEAU, 2015)
} 
litigantes suportassem uma maior proporção das custas. Inviabilizase, com a fórmula atual, a própria prevenção do conflito, pois, para as empresas, é mais barato litigar do que internamente alocar recursos para uma solução extrajudicial, não despendendo, portanto, esforços para a autocomposição, o que leva, inevitavelmente, à utilização irresponsável do Judiciário a custo praticamente zero. (PIMENTEL, 2017)

Uma empresa igualmente considera a morosidade como elemento do custo para litigar. Se é baixo o custo para litigar em juízo e se esse sistema é moroso, é possível que a empresa prefira investir o valor que despenderia em uma solução consensual em outros fins, utilizando a morosidade como forma de favorecer seu investimento.

Essas empresas encontram no baixo valor das custas e na morosidade judicial - causada, inclusive, pela sobrecarga do serviço judicial, por sua vez gerada pelas baixas custas, em um sistema cíclico de causa e efeito - estímulo para o descumprimento dos direitos dos cidadãos e para a recusa injustificada de resolver os conflitos de forma consensual.

Esse movimento, que exclui os bons litigantes e atrai os litigantes ruins, é denominado "seleção adversa" por Ivo Teixeira Gico Jr., que assim o explica:

Cada vez mais pessoas deixarão de usar o Judiciário para fazer valer seus direitos e cada vez mais pessoas passarão a usar o Judiciário para postergar ou anular suas obrigações. É a antítese da função social do Judiciário. [...] detentores legítimos de direitos são afastados do Judiciário, enquanto agentes não detentores de direitos são atraídos justamente por causa da morosidade judicial para postergar o adimplemento. Em uma espécie de Lei de Gresham, bons litigantes são excluídos do mercado de litígios e litigantes ruins são atraídos a ele. As políticas públicas de acesso indiscriminado ao Judiciário, quando isoladamente consideradas, excluem usuários marginais pela morosidade e, ao fim e ao cabo, reduzem a utilidade social do Judiciário devido à sua sobreutilização, um resultado certamente trágico. (GICO JR., 2014)

Segundo Benjamin Tabak (2017), em países nos quais as custas processuais se aproximam ao máximo do custo efetivo do processo, há o desestímulo na judicialização das demandas e a priorização de outros métodos de solução de conflitos, sendo a via adversarial a última opção. 
Com efeito, a taxa de litigiosidade está diretamente relacionada às custas processuais, embora não se possa limitá-la a esse único fator. Por exemplo, o Tribunal de Justiça da Paraíba - TJ/PB, cuja constitucionalidade da lei de custas é questionada no STF7 (BRASIL, 2017), possui o segundo maior valor de custas em uma ação judicial: R\$100.000,00, ficando atrás apenas do Tribunal de Justiça do Piauí - TJ/PI. Por outro lado, o TJ/PB é o tribunal de pequeno porte com o menor número de novos casos por cem mil habitantes e o quarto entre todos os tribunais de justiça (BRASIL, 2019, 2020a). Tais dados indicam a relação defendida neste artigo, de que quanto menores os custos processuais, maior a taxa de litigiosidade e vice-versa.

As custas processuais devem, em verdade, corresponder, ao máximo, ao custo real do processo, diminuindo, consequentemente, o financiamento público. As baixas custas, em vez de possibilitar o acesso à justiça, acabam por restringi-lo, tornando o Judiciário monopólio dos grandes litigantes, que possuem maior capacidade financeira.

\section{UM NOVO OLHAR SOBRE O ACESSO À JUSTIÇA: BREVE REFLEXÃO}

$\bigcirc$ art. 5, XXXV, da Constituição Federal prescreve que "a lei não excluirá da apreciação do Poder Judiciário lesão ou ameaça a direito" e representa os princípios da inafastabilidade da jurisdição e do acesso à justiça.

À primeira vista, qualquer elemento que possa vir a condicionar ou limitar o acesso ao Poder Judiciário, como uma alteração no tratamento das custas processuais que implique menor subsídio estatal, deveria ser rechaçado, à luz do citado dispositivo constitucional.

Essa interpretação, somada a outros fatores, como a ampliação dos direitos fundamentais e sociais, a criação dos juizados especiais etc., contudo, tem levado a uma sobreutilização do Judiciário, a ponto de

\footnotetext{
7 Após o voto do relator, Ministro Edson Fachin, julgando parcialmente procedente o pedido para declarar a inconstitucionalidade do art. 3ㅇ da Lei n. 8.071/2006, sob o argumento de que o aumento do teto das taxas judiciárias de 200 para 900 Ufirs ofende os princípios do devido processo legal, da razoabilidade e da proporcionalidade, o Ministro Dias Toffoli abriu divergência e julgou improcedente o pedido, por entender que não há desproporcionalidade diante dos valores consignados. O julgamento foi suspenso pelo pedido de vista do Ministro Gilmar Mendes e incluído na pauta de julgamento do dia 21 de maio de 2021. (BRASIL, 2020b).
} 
criar um paradoxo, o de que o acesso à justiça poderia ser considerado um acesso à injustiça, dada a morosidade do sistema judicial.

É preciso, então, repensar esse acesso, sob pena de se colocar em risco o próprio Estado de Direito. Sobre tal ponto, esclarecem Maria Tereza Sadek e outros:

[...] sem uma Justiça acessível e eficiente, colocase em risco o Estado de Direito. [...] Pois a excessiva facilidade para um certo tipo de litigante ou estímulo à litigiosidade podem transformar a Justiça em uma Justiça não apenas seletiva, mas sobretudo inchada. Isto é, repleta de demandas que pouco têm a ver com a garantia de direitos - esta sim é uma condição indispensável ao Estado Democrático de Direito e às liberdades individuais. (SADEK, 2001, p. 41)

Kazuo Watanabe (2019b, p.36) explica que o acesso à justiça se refere, efetivamente, ao "acesso à ordem jurídica justa, e não mero acesso aos órgãos judiciários para obtenção de solução adjudicada por meio da sentença”. Em outras palavras, não se limita à possibilidade de ingressar no Judiciário, mas engloba conferir ao cidadão a adequada resolução do conflito, o que implica observar os princípios da eficiência e da duração razoável do processo.

Isso porque o Judiciário é um bem rival, conforme ensina Ivo Teixeira Gico Jr. (2014, p. 178), o que significa que "quanto mais pessoas utilizarem o Judiciário, menos útil ele será para a coletividade, pois menor será sua capacidade de prestar serviços públicos adjudicatórios". Quanto mais pessoas buscarem a via adversarial - mesmo não sendo imprescindível -, pior será a prestação do serviço, gerando a sensação de insatisfação tanto naqueles que não precisariam demandar no Judiciário e poderiam resolver mais rápida e efetivamente sua demanda por outros meios quanto naqueles que precisam do sistema adversarial, que, devido à sua sobreutilização, torna-se moroso e não efetivo.

Fabrício Lunardi sintetiza a questão da seguinte forma:

Assim, se compreendido o acesso à justiça numa concepção mais global, no sentido de que significa tanto ingresso no Poder Judiciário quanto resposta rápida e adequada ao litígio, pode-se dizer que a ampliação do acesso à justiça também implica paradoxalmente uma restrição ao acesso. Isto é, quando se amplia demasiadamente a possibilidade de ingresso, pode-se estar restringindo a possibilidade de uma resposta rápida e adequada aos conflitos judicializados. (LUNARDI, 2019, p. 71) 
O atual volume de processos não permite que se atenda as demandas do cidadão com a dinamicidade e a qualidade esperadas. Nos dizeres de Sales (2003, p. 12), "é praticamente impossível proferir uma sentença de qualidade quando os magistrados não possuem tempo suficiente para analisar com atenção todas as questões que envolvem o caso sub judice".

\section{A GESTÃO PROCESSUAL POR INTERMÉDIO DAS CUSTAS PROCESSUAIS: CORREÇÃO DE DADOS PROCESSUAIS, GRATUIDADE DA JUSTIÇA E INTERESSE RECURSAL}

O case management ${ }^{8}$ inglês representa a experiência bemsucedida de que a gestão de processos pelos juízes é fundamental para se atingir uma jurisdição de alta performance, com a redução no tempo de tramitação das demandas, o uso proporcional dos recursos e a substituição da tradição adversarial.

Parte-se da premissa de que o papel do magistrado enquanto gestor do processo é crucial para que haja um equilíbrio no acesso à justiça e reflete a preocupação constante de otimização do processo, traduzindo-se a gestão processual em poder-dever do juiz.

Nessa perceptiva, é fato que os juízes podem contribuir diretamente para o agravamento ou para a solução da crise do Judiciário (GICO JR., 2014), porquanto o sistema processual vigente confere ao magistrado o poder de gerir o processo. O compromisso do juiz, contudo, deve ir além do dever legal de impulso oficial, englobando aspectos que não possuem ligação direta com a relação jurídica controvertida, mas que impactam a prestação jurisdicional, como a gestão cartorária e a gestão de pessoas.

As escolas judiciais possuem relevante papel na formação desse juiz multidisciplinar e na criação e no desenvolvimento da consciência de que um bom magistrado, mais do que um bom julgador, deve ser um bom gestor, com vistas à otimização e à concentração de atos processuais, sob pena de aumento dos custos dos processos, pois o custo processual se eleva a cada ato praticado desnecessariamente. (LUNARDI, 2019)

\footnotetext{
8 O case management é o sistema inglês de gestão processual introduzido pelo Civil Procedure Rules - CPR, de 1998, fruto da Woolf's Reform. Tem como alicerce o deslocamento da gestão dos processos dos advogados para os juízes. (ALMEIDA, 2011)
} 
Isso revela a importância de uma análise inicial e criteriosa das ações além do direito material controvertido, incluindo a concessão da justiça gratuita, a correta atribuição do valor da causa e a devida vinculação à classe e ao assunto processual no sistema do Processo Judicial eletrônico - PJe, pois são elementos que impactam diretamente nas custas processuais e, portanto, na decisão de litigar.

Em 5 de dezembro de 2020, foi publicada a Lei Estadual n. 17.116, que consolida o regime jurídico da taxa judiciária e das custas processuais devidas ao Poder Judiciário do Estado de Pernambuco, editada com o objetivo de modernizar e facilitar a cobrança das custas judiciais e de conceder-lhes um tratamento adequado. Com o mesmo objetivo, - CNJ enviou projeto de lei ao Congresso Nacional, em setembro de 2020 (MONTENEGRO, 2020), ainda pendente de andamento, conforme consulta realizada à Câmara dos Deputados pelo canal Fale Conosco, em 27 de janeiro de 2021.

Mesmo com essas propostas e alterações legislativas, o tratamento adequado das custas perpassa pela atuação do magistrado gestor. A mera incorreção da classe processual e da atribuição do valor da causa, o que é feito pela parte autora por ocasião do protocolo do processo no sistema PJe, repercute diretamente no valor das custas, pois altera sua base de cálculo.

Se não houver uma efetiva fiscalização pelos magistrados, de forma direta, ou indiretamente pelos servidores a eles vinculados, quanto à correta identificação dos dados processuais, incluindo a classe processual e o valor da causa, a alteração legislativa não surtirá o efeito almejado e o tratamento das custas processuais continuará a criar distorções no sistema judicial.

Especificamente em relação à justiça gratuita, houve, no Judiciário, um incremento da concessão de assistência judiciária gratuita e estimase que cerca de $75 \%$ das ações em tramitação não tenham ônus para o jurisdicionado, em virtude da isenção ou daqueles feitos não sujeitos a custas, como os que tramitam nos juizados especiais (BRASIL, 2019).

Benjamin Tabak alerta que:

[...] a gratuidade incentiva a proliferação dos processos e que a implicação aos litigantes, de arcar com os custos do processo, desempenha importante papel na política judiciária de impedir abusos no direito de demandar e que, automaticamente, ocorreria uma maior procura 
dos meios extrajudiciais de solução dos conflitos, que são baratos e eficazes. (TABAK, 2017, p. 473)

Conceder a justiça gratuita a quem dela não necessita é, por vias transversas, negar o acesso a quem efetivamente precisa, na ótica de que o Judiciário é um recurso rival, conforme acima referenciado, porquanto a concessão indiscriminada da assistência judiciária gratuita pode levar à sobreutilização da Justiça.

Deve o magistrado se ater aos critérios legais e jurisprudenciais quanto à concessão da justiça gratuita, pois este benefício impacta diretamente na taxa de litigiosidade, na taxa recursal e na taxa de congestionamento, na perspectiva de que, se interposto recurso, o tempo de tramitação do feito será maior.

Wilson Pimentel (2017) fez relevante análise quanto ao fator "justiça gratuita" quando examinou o sistema recursal da justiça cível e do juizado especial cível no âmbito do TJ/RJ. Concluiu ele que o benefício foi requerido em 50\% dos casos e deferido em 90\% dos processos, aproximadamente, e que aqueles que gozam da justiça gratuita recorrem em 83,26\% das vezes, contra 52,17\% daqueles que pagam as custas processuais para recorrer. Infere-se, portanto, que a gratuidade das custas recursais pode ser considerada um estímulo à interposição de recursos.

É importante ressaltar que eventual aumento no valor das custas processuais para se aproximar dos custos efetivos do processo não tem o condão de inibir o acesso dos hipossuficientes financeiros, pois a legislação brasileira possui mecanismos para garantir a acessibilidade da população vulnerável aos serviços judiciais", sem se olvidar do acesso à justiça sob o viés da "ordem jurídica justa", conforme reflexões expostas no item 4 deste artigo.

A Constituição Federal10 prevê o benefício da justiça gratuita àqueles que comprovarem não possuírem recursos financeiros. Destacase a exigência constitucional da comprovação da hipossuficiência financeira, de modo que é necessário, na perspectiva do magistrado

9 O Código de Processo Civil revogou os arts. 2a a 4ำ da Lei n. 1.060, de 5 de fevereiro de 1950 e passou a disciplinar a concessão da gratuidade da justiça nos arts. 98 a 102. O art. 98, §§ 5 e 6, trata, especificamente, sobre a redução e o parcelamento das custas. (BRASIL, 2015)

10 Art. 5, LXXIV: O Estado prestará assistência jurídica integral e gratuita aos que comprovarem insuficiência de recursos. (BRASIL, 1988) 
gestor, a verificação efetiva quanto à disponibilidade de recursos financeiros pela parte requerente do benefício, constituindo a declaração de hipossuficiência presunção relativa e início de prova dessa condição.

Defende-se, pois, que o magistrado, de ofício, na dúvida ou à luz de elementos que evidenciem a falta dos pressupostos para a concessão da gratuidade, intime a parte requerente para comprovar sua hipossuficiência e a necessidade de gozar do benefício. Atuar de modo diverso, ou seja, adotar uma interpretação ampliativa da concessão da gratuidade, traz severos riscos ao próprio Poder Judiciário, conforme esclarece Fabrício Lunardi (2019, p. 71):

Desse modo, quando, por exemplo, o próprio Judiciário faz uma interpretação ampliativa da gratuidade judiciária, é preciso lembrar que essa decisão gera um benefício para o litigante, podendo ampliar o acesso à justiça, mas, de outro, onera toda a sociedade, que está pagando um elevado valor para esse processo. Além disso, essa ampliação do acesso à justiça pode implicar uma sobreutilização do Judiciário, de modo que o processo judicial passa a ser o principal mecanismo de solução de conflitos da sociedade.

A assistência judiciária gratuita, contudo, não implica, necessariamente, a isenção total das custas processuais, visto que a legislação atual aponta outros mecanismos que devem ser considerados pelo magistrado antes de conceder a gratuidade completa, como a possibilidade de redução e parcelamento, além da concessão para determinado ato ou conjunto de atos processuais. Assim é que, exemplificadamente, a parte pode ter recursos para pagar as custas iniciais, mas não dispor de condições para arcar com os honorários periciais, incidindo a gratuidade apenas em relação às despesas com o perito. Em outros casos, a parte não pode pagar integralmente as custas, mas pode dividi-la em duas ou três parcelas. E, há, ainda, situações em que a parte pode pagar metade ou um terço do total das custas processuais. (WAMBIER, 2016, p. 407)

A modulação dos efeitos da gratuidade reclama, mais uma vez, uma postura gerencial do magistrado e a verificação ao longo de todo o processo se subsiste a hipossuficiência ou se ela é integral ou parcial, inclusive com vistas a evitar o abuso de direito e conferir às partes igualdade de tratamento. 
Relativamente à taxa de recorribilidade, um tribunal que cobra percentual maior de taxa judicial para recorrer tende a ter menos recursos que um tribunal que cobra taxa menor, pois o incentivo recursal deste é maior do que daquele.

Para medir o impacto das custas recursais como elemento racional na escolha de litigar ou de continuar litigando, na referenciada pesquisa realizada pela Fundação Getulio Vargas - FGV no TJ/RJ, concluiu-se que o índice recursal do juizado especial cível é menor do que o da Justiça cível, porque nesta o custo para recorrer era de $\mathrm{R} \$ 299,36$ (valor da apelação), enquanto naquela era de $\mathrm{R} \$ 1.200,00$. Em outras palavras, dado o baixo custo para recorrer, o índice de recorribilidade da Justiça cível foi $287 \%$ maior do que o grau de recorribilidade do juizado especial cível.

Vê-se, pois, que o interesse recursal é inversamente proporcional ao valor das custas para recorrer, de modo que se pode concluir que as baixas custas recursais implicam maior tempo de tramitação do feito e, por consequência, maior taxa de congestionamento. Essa lógica, que impacta negativamente os números do Judiciário e sobrecarrega a instância de $2^{\circ}$ grau com recursos, muitas vezes protelatórios, também foi objeto de destaque pelo $\mathrm{CNJ}$ :

Portanto, percebe-se que o sistema de custas pode ser um incentivador da proposição de recursos, uma vez que, em regra, é muito mais barato interpor recursos, seja de segundo grau, ou recursos especiais, extraordinários e de revista, do que propor ações originárias. Assim, para uma parte que despendeu uma quantia significativa para iniciar a litigância, diante de um montante pequeno por ela já devido em termos de custas, tenderá a ser economicamente mais interessante a interposição de recursos. (BRASIL, 2019)

\section{CONCLUSÃO}

A resolução da crise do Judiciário perpassa, obrigatoriamente, pelo tratamento adequado das custas dos processos, o que inclui a reformulação legislativa e a distinta atuação do magistrado gestor.

Esse tratamento adequado não implica um aumento indiscriminado das custas processuais, podendo haver, inclusive, a redução destas como incentivo à adoção de métodos autocompositivos pré-processuais e a 
diminuição do número de novos processos no Judiciário. Por exemplo, na Inglaterra, aquela parte que busca a mediação e envida esforços na sua consecução antes de ingressar no sistema adversarial é beneficiada com a redução de custas em eventual demanda judicial. (ALMEIDA, 2011)

O que deve haver é a aproximação do valor das custas processuais ao custo efetivo do processo, com a consequente diminuição do investimento estatal. $\bigcirc$ aumento da contraprestação pela parte litigante não pode ser visto como obstáculo ao acesso à justiça, pois, em virtude dos baixos custos processuais atuais, entre litigar e buscar a via consensual para solucionar os conflitos, os grandes litigantes optam pela via adversarial e se valem da morosidade para postergar o cumprimento de suas obrigações. Além disso, manter o financiamento público do processo judicial no percentual de quase 90\% é obstaculizar os métodos pré-processuais de resolução de conflitos.

Partindo de uma concepção atualizada da jurisdição e do acesso à justiça, voltada à célere, efetiva e adequada resolução de conflitos, em harmonia com os preceitos constitucionais e os objetivos do Estado e em respeito à maximização dos direitos fundamentais, não se pode admitir a subvenção das custas processuais pela sociedade nos níveis atuais, de modo que a aproximação das custas ao valor real do processo não implica ofensa ao art. 5, XXXV, da Constituição Federal.

Não se defende que o Judiciário possa auferir lucros com a cobrança de custas, mas que seja possível diminuir o prejuízo e a sobrecarga para a coletividade, sobretudo em face de grandes litigantes com notória capacidade financeira.

O magistrado gestor possui relevante papel no tratamento adequado das custas, como verdadeiro instrumento de gestão processual, seja na correta e criteriosa análise do benefício da justiça gratuita, seja na verificação dos elementos processuais que impactam no valor das custas processuais - valor da causa, classe processual etc.

Não se desconhece que outros elementos influenciam na escolha de recorrer, como a compatibilidade da decisão com o entendimento jurisprudencial, o envolvimento emocional no conflito etc., mas, isolado o elemento "custo", percebe-se, claramente, que este possui grande influência na decisão das partes.

Um tratamento adequado das custas processuais, portanto, tem o condão de, a um só tempo, atuar como indutor da transformação 
cultural, favorecendo os métodos autocompositivos de solução dos conflitos, reconhecidamente mais baratos, e como filtro de novos processos no Judiciário e de redução do tempo de tramitação nas cortes judiciais, possibilitando a diminuição da taxa de congestionamento e da morosidade e afastando os litigantes habituais e as demandas predatórias, com o consequente fortalecimento do acesso à justiça, correspondente a uma tutela judicial efetiva e justa. 


\section{REFERÊNCIAS}

ALMEIDA, Diogo Assumpção Rezende de. O case management inglês: um sistema maduro? Revista Eletrônica de Direito Processual, Rio de Janeiro, v. 7, n. 7, p. 287-335, 2011. Disponível em: https://www.epublicacoes.uerj.br/index.php/redp/article/view/21127/15217. Acesso em: 6 fev. 2021.

BRASIL. Conselho Nacional de Justiça. 100 maiores litigantes (2011). Brasília, DF: CNJ, 2012. Disponível em: https://www.cnj.jus.br/wpcontent/uploads/2011/02/100_maiores_litigantes.pdf. Acesso em: 28 jan. 2021.

BRASIL. Conselho Nacional de Justiça. Diagnósticos das custas processuais praticadas nos tribunais. Brasília, DF: CNJ, 2019. Disponível em: https://www.cnj.jus.br/wp-content/uploads/2019/11/relat_custas_ processuais2019.pdf. Acesso em: 25 jan. 2021.

BRASIL. Conselho Nacional de Justiça. Justiça em Números 2020: ano-base 2019. Brasília, DF: CNJ, 2020a. Disponível em: https://www. cnj.jus.br/wp-content/uploads/2020/08/WEB-V3-Justi\%C3\%A7a-emN\%C3\%BAmeros-2020-atualizado-em-25-08-2020.pdf. Acesso em: 25 jan. 2021.

BRASIL. Constituição (1988). Constituição da República Federativa do Brasil 1988. Brasília, DF: Presidência da República, [2020]. Disponível em: http://www.planalto.gov.br/ccivil_03/constituicao/constituicao.htm. Acesso em: 19 jan. 2021.

BRASIL. Lei n. 1.060, de 5 de fevereiro de 1950. Estabelece normas para a concessão de assistência judiciária aos necessitados. Brasília, DF: Presidência da República, [2015]. Disponível em: http://www.planalto. gov.br/ccivil_03/leis/11060.htm Acesso em: 20 maio 2021.

BRASIL. Lei n. 5.172, de 25 de outubro de 1966. Código Tributário Nacional. Brasília, DF: Presidência da República, 2007. Disponível em: http://www.planalto.gov.br/ccivil_03/leis/15172compilado.htm. Acesso em: 29 jan. 2021.

BRASIL. Lei n. 13.105, de 16 de março de 2015. Código de Processo Civil. Brasília, DF: Presidência da República, 2015. Disponível em: http:// www.planalto.gov.br/ccivil_03/_ato2015-2018/2015/lei/113105.htm. Acesso em: 28 jan. 2021. 
BRASIL. Supremo Tribunal Federal. Ação Direito de Inconstitucionalidade n. 5.688/PB. Taxa judiciária. Relator: Min. Edson Fachin, 2017. Disponivel em: http://portal.stf.jus.br/processos/detalhe. asp?incidente=5167293. Acesso em: 22 maio 2021.

BRASIL. Supremo Tribunal Federal. Informativo STF n. 966. Brasília, DF: Supremo Tribunal Federal, 2020b. Disponivel em: http:// www.stf.jus.br/arquivo/informativo/documento/informativo966. htm\#Majora\%C3\%A7\%C3\%A30\%20de\%20taxa\%20e\%20custas\%20 judiciais. Acesso em: 22 maio 2021.

BRASIL. Supremo Tribunal Federal. Representação n. 1.077/RJ. Taxa judiciária é tributo da espécie taxa. Essa natureza jurídica não foi alterada com a edição da Emenda constitucional n. 7/77. Relator: Min. Moreira Alves, 28 de março de 1984. Brasília, 1984. Disponível em: http:// redir.stf.jus.br/paginadorpub/paginador.jsp?docTP=AC\&doclD=263851. Acesso em: 26 jan. 2021.

CARLOS, Helio Antunes; SILVA, Renan Sena. A necessária mudança na postura dos atores processuais na lógica da justiça multiportas. In: SICA, Heitor et al. (org.). Temas de direito processual contemporâneo: III Congresso Brasil-Argentina de Direito Processual. Serra: Milfontes, 2019. v. 2.

FUX, Luiz; BODART, Bruno. Processo civil e análise econômica. 2. ed. Rio de Janeiro: Forense, 2021.

GICO JR., IVo Teixeira. Análise econômica do processo civil. São Paulo: Foco, 2020.

GICO JR., Ivo Teixeira. A tragédia do Judiciário. Revista de Direito Administrativo, Rio de Janeiro, v. 267, p. 163-198, set./dez. 2014. Disponível em: http://bibliotecadigital.fgv.br/ojs/index.php/rda/article/ viewFile/46462/44453. Acesso em: 26 jan. 2021.

GICO JR., Ivo Teixeira; ARAKE, Henrique Haruki Cavalcante. Taxa de recorribilidade, taxa de reversibilidade e eficiência judicial. Revista Eletrônica do Curso de Direito da UFSM, Rio Grande do Sul, v. 14, n. 1, e31820, jan./abr. 2019. Disponível em: https://periodicos.ufsm.br/ revistadireito/article/view/31820. Acesso em: 3 dez. 2020.

LUNARDI, Fabrício Castagna. Curso de direito processual civil. 3. ed. rev. atual. e ampl. São Paulo: Saraiva, 2019. 
MACKAAY, Ejan; ROUSSEAU, Stéphane. Análise econômica do direito. 2. ed. São Paulo: Atlas, 2015.

MARINONI, Luiz Guilherme; ARENHART, Sérgio Cruz; MITIDIERO, Daniel. Código de processo civil comentado. 6. ed. rev. São Paulo: Revista dos Tribunais, 2020.

MEDINA, José Miguel Garcia. Código de processo civil comentado. 6. ed. rev. São Paulo: Thomson Reuters Brasil, 2020.

MONTENEGRO, Manuel Carlos. CNJ entrega ao Congresso proposta de lei para disciplinar custas judiciais. Notícias CNJ/Agência CNJ de Notícias, Brasília, 2020. Disponível em: https://www.cnj.jus.br/cnjentrega-ao-congresso-proposta-de-lei-para-disciplinar custas-judiciais/. Acesso em: 28 jan. 2021.

NEVES, Daniel Amorim Assumpção. Novo CPC: Código de processo civil: Lei 13.105/2015: inovações, alterações, supressões comentadas. 3. ed., rev., ampl. e atual. São Paulo: Método, 2016. 695 p.

PERNAMBUCO. Lei $\mathbf{n}$. 17.116, de 4 de dezembro de 2020. Consolida o regime jurídico da taxa judiciária e das custas processuais devidas ao Poder Judiciário do Estado de Pernambuco. Recife, 2020. Disponível em: https://legis.alepe.pe.gov.br/texto.aspx?id=53619\&tipo=. Acesso em: 28 jan. 2021.

PIMENTEL, Wilson. Acesso responsável à justiça: o impacto dos custos na decisão de litigar. 2017. Dissertação (Mestrado em Direito) - Escola de Direito do Rio de Janeiro, Fundação Getulio Vargas, Rio de Janeiro, 2017. Disponível em: http://bibliotecadigital.fgv.br/ dspace/bitstream/handle/10438/21988/Pimentel\%2C\%2OWilson.\%20 Acesso\%2Orespons\%C3\%A1vel\%20\%C3\%A0\%20justi\%C3\%A7a\%2OUL. pdf? sequence=1\&isAllowed=y. Acesso em: 26 jan. 2021.

PORTO, Antônio Maristrello; GAROUPA, Nuno. Curso de análise econômica do direito. São Paulo: Atlas, 2020.

REMÍGIO, Hipólito Gadelha. Custos no serviço público: um modelo aplicado ao custeio dos processos judiciais. 2002. Dissertação (Mestrado em Contabilidade) - Programa multi-institucional e interregional de pós-graduação em Ciência Contábeis, UnB, UFPB, UFPE e UFRN, Brasília, 2002. Disponivel em: http://ppgcont.unb.br/images/ PPGCCMULTI/mest_dissert_009.pdf. Acesso em: 25 jan. 2021. 
SADEK, Maria Tereza (org.). Acesso à justiça. São Paulo: Fundação Konrad Adenauer, 2001. (Série Pesquisas, n. 23).

SALES, Lília Maia de Morais. Justiça e mediação de conflitos. Belo Horizonte: Del Rey, 2003.

TABAK, Benjamin Miranda. O custo da justiça à luz das modernas técnicas de gestão judicial e da análise comportamental do direito.

Revista jurídica, Curitiba, v. 3, n. 48, p. 458-481, 2017. Disponível em: http://www.mpsp.mp.br/portal/page/portal/documentacao_e_ divulgacao/doc_biblioteca/bibli_servicos_produtos/bibli_informativo/ bibli_inf_2006/Rev-Juridica-UNICURITIBA_n.48.20.pdf. Acesso em: 27 jan. 2021.

WAMBIER, Teresa Arruda Alvim et al. Breves comentários ao novo Código de processo civil. 3. ed. rev. São Paulo: Revista dos Tribunais, 2016.

WATANABE, Kazuo. Acesso à ordem jurídica justa: conceito atualizado de acesso à justiça, processos coletivos e outros estudos. Belo Horizonte: Del Rey, 2019a.

WATANABE, Kazuo. Estratégias para a solução pacífica dos conflitos de interesses. In: CURY, Augusto (org.). Soluções pacíficas de conflitos para um Brasil moderno. Rio de Janeiro: Forense, 2019b. p. 27-37.

XIMENES Júlia Maurmann; De Sordi, N. A. D.; SILVA, J. A.; PRATA, A. C. A. C.; FERREIRA, G. V. Índice de desempenho da Justiça 2013 e estudo comparado sobre a evolução do Judiciário 2010 - 2013. Brasília, 2014. (Relatório de pesquisa). Disponível em: https://www.conjur.com.br/dl/ idjus2013.pdf. Acesso em: 27 jan. 2021. Janeiro: Forense, 2019b. p. 27-37.

XIMENES Júlia Maurmann; De Sordi, N. A. D.; SILVA, J. A.; PRATA, A. C. A. C.; FERREIRA, G. V. Índice de desempenho da Justiça 2013 e estudo comparado sobre a evolução do Judiciário 2010 - 2013. Brasília, 2014. (Relatório de pesquisa). Disponível em: https://www.conjur.com.br/dl/ idjus2013.pdf. Acesso em: 27 jan. 2021. 